present in the dermis (fig 4). The increased zinc concentration in lente and protamine zinc preparations or the presence of fish protamine in isophane and protamine zinc insulins may enhance the immunological response to injected insulin. ${ }^{18}$ The remarkable female preponderance in this and other series of patients with lipoatrophy is difficult to explain immunologically. Lipoatrophy may be more obvious in women, in whom there is more subcutaneous tissue available for dramatic change.

Lipoatrophy at sites remote from injection, such as the breasts and face, has occasionally been reported and is difficult to explain by any theory of insulin-induced lipoatrophy. We think it much more likely that if such cases occur they represent the coexistence of insulin-dependent diabetes with some other form of lipodystrophy. ${ }^{19} 20$

We thank the many colleagues who have helped in collecting appropriate skin biopsy and blood specimens, the technical staff of the immunology department for their skilled help in preparing material for immunofluorescence and performing the insulin-binding capacity assays, Alasdair Mackay for reviewing the histological findings, and Anne Willington for typing the manuscript. The insulin-binding capacity assay was developed during tenure of a research grant from the British Diabetic Association. The valuable help of Novo Laboratories Ltd is also gratefully acknowledged.

Requests for reprints should be addressed to Dr W G Reeves.

\section{References}

${ }^{1}$ Wright $\mathrm{AD}$, Walsh $\mathrm{CH}$, Fitzgerald MG, Malins JM. Very pure porcine insulin in clinical practice. $\mathrm{Br}$ Med $\mathcal{f} 1979 ; \mathrm{i}: 25-7$.

2 Renold AE, Winegrad AI, Martins DB. Diabete sucré et tissue adipeux. Helvetica Medica Acta 1957;24:322-7.

3 Paley RG. Lipodystrophy following insulin injections. Metabolism 1953;2: 201-10.
${ }^{4}$ Poulsen JE, Deckert T. Insulin preparations and the clinical use of insulin Acta Med Scand [Suppl] 1976;601:197-245.

5 Marriott DW, Reeves WG. Immunofluorescence. In: Bancroft JD, Stevens A, eds. Theory and practice of histological techniques. Edinburgh: Churchill Livingstone, 1977:387-93.

- Reeves WG, Kelly U. An immunochemical method for the quantitation of insulin antibodies. $f$ Immunol Methods (in press).

${ }^{7}$ Marble A. In: Ellenberg M, Rifkin $\mathrm{H}$, eds. Diabetes mellitus: theory and practice. New York: McGraw Hill, 1970:638.

8. Watson $D$, Vines $R$. Variations in the incidence of lipodystrophy using different insulins. Med $\mathcal{f}$ Aust 1973; $: 248-50$.

- Carmichael EA, Graham G. Local fat atrophy following insulin injections. Lancet $1928 ; \mathrm{i}: 601$.

${ }^{10}$ Avery $\mathrm{H}$. Insulin fat atrophy: a traumatic atrophic panniculitis. $\mathrm{Br} \mathrm{Med} \mathcal{F}$ $1929 ; \mathrm{i}: 597$.

11 Kumar D, Miller LV, Mehtalia SD. Use of dexamethasone in treatment of insulin lipoatrophy. Diabetes $1977 ; 26: 296-9$.

12 Renold AE, Marble A, Fawcett DW. Action of insulin on deposition of glycogen and storage of fat in sub-cutaneous tissue. Endocrinology 1950 46:55.

${ }^{13}$ Malins JM. Clinical diabetes mellitus. London: Eyre and Spottiswoode, $1968: 408$.

14 Underwood LE, Voina SJ, Vanwyk JJ. Restoration of growth by human growth hormone (ROOS) in hypopituitary dwarfs immunized by other human growth hormone preparations: clinical and immunological studies. F Clin Endocrinol Metab 1974;38:288-97.

${ }^{15}$ Arthus M. Injections répétées de sérum de cheval chez le lapin. Comptes Rendue Societé Biologie (Paris) 1903;55:817-20.

${ }^{16}$ Arthus $M$, Breton. M. Lésions cutanées produites par les injections de sérum de cheval chez le lapin anaphylactisé par et pour se sérum. Comptes Rendue Societé Biologie (Paris) 1903;55:1478-80.

17 Cochrane G, Dixon FJ. Immune complex injury. In: Samter M, ed. Immunological diseases. Boston: Little Brown, 1978:210-29.

${ }^{18}$ Reeves WG. Immunology of diabetes and insulin therapy. Recent Advances in Clinical Immunology (in press).

19 Crome P, Keen H. Partial lipodystrophy and insulin-resistant diabetes. Diabete Metab 1978;4:81-4.

${ }^{20}$ Kodama S, Kasuga M, Seki A, et al. Congenital generalized lipodystrophy with insulin-resistant diabetes. Eur $\mathcal{F}$ Pediatr 1978;127:111-9.

(Accepted 31 March 1980)

\title{
Intermittent claudication: Is a supervised exercise class worth while?
}

\author{
P C CLIFFORD, P W DAVIES, JULIET A HAYNE, R N BAIRD
}

\section{Summary and conclusions}

Twenty-one patients (19 men and two women) with disabling exercise-related leg pain attended a physiotherapy department on one afternoon each week for an exercise training programme lasting one month. The clinical diagnosis of intermittent claudication and localisation of the atherosclerotic occlusions were confirmed in all but one case by pulse volume recordings and segmental Doppler systolic pressure measurements. Two patients whose symptoms worsened underwent arterial reconstruction. Post-training assessment at six months showed that the remaining 18 patients walked $80 \%$ further and performed $\mathbf{7 5 \%}$ more step-ups. They

\footnotetext{
Departments of Surgery and Physiotherapy, Bristol Royal Infirmary, Bristol BS2 8HW

P C CLIFFORD, FRCS, British Heart Foundation research fellow $P$ W DAVIES, MIBIOL, chief technician

JULIET A HAYNE, MCSP, senior physiotherapist

R N BAIRD, CHM, FRCS, consultant senior lecturer in surgery
}

also felt much healthier, having unduly restricted their activities before because they had feared the onset of ischaemic leg pain.

These results suggest that supervised exercise training is a simple and effective method of treating patients with intermittent claudication.

\section{Introduction}

The beneficial effects of daily walks and physical training in intermittent claudication were first described by Foley ${ }^{1}$ and confirmed by American ${ }^{2}$ and Scandinavian ${ }^{3-6}$ reports. The traditional view is that sufferers should slow down, stop smoking, and hope for the best. ${ }^{7}$ Patients with intermittent claudication tend to eschew physical exercise since they fear the onset of ischaemic leg pain. Nevertheless, they also risk becoming completely housebound or dependent on the car. Those attending hospital outpatient clinics have usually already been given at least one vasodilator drug without success, and most, who are not offered arterial reconstruction, look to the vascular surgeon for effective medical treatment. We have evaluated the usefulness of an exercise class for patients with intermittent claudication. 


\section{Patients and methods}

We studied 21 patients (19 men and two women) aged under 65 who complained of leg pain or calf pain on walking less than 250 yards $(230 \mathrm{~m})$. None showed sufficiently severe symptoms (pain at rest or gangrene) to warrant an immediate arteriogram or had clinically evident cardiovascular disease or pulmonary diseasethat is, resting electrocardiograms and chest radiographs were normal. All lived within 20 miles $(32 \mathrm{~km})$ of the hospital. Arterial ischaemia in the legs was confirmed by pulse volume recordings and segmental limb pressure measurements with a sphygmomanometer cuff and $5 \mathrm{MHz}$ pencil-probe Doppler ultrasound Velocimeter to ensure that the exercise-related pain was ischaemic and not neurogenic or orthopaedic. Ankle pulse volumes and pressures were measured at rest and after exercise for one minute either on a bicycle ergometer at $500 \mathrm{kpm} / \mathrm{min}(294.3 \mathrm{kw})$ or on a treadmill at $2 \mathrm{~km} / \mathrm{h}$ on a $10 \%$ gradient. The patients were restudied at six weeks and again at six months.

In the vascular outpatient clinic the aim of the daily exercise programme and the importance of adhering to it were emphasised, though the details were not disclosed. Patients were advised to stop smoking and saw the dietitian, who recommended replacing part of the animal-fat content of their diets with polyunsaturated fat. A low carbohydrate diet was also advised for several patients who were overweight.

The patients were shown the exercises on their first visit to the physiotherapy department (table). They were taught a simple daily

Programme of exercises performed at home by patients with intermittent claudication

\begin{tabular}{ll}
\hline Lying: & Pull ankles up and down then round in a circle \\
Lying: & Raise straight leg for count of three and slowly lower; repeat for other \\
leg & \\
Lying: & Bend and straighten alternate legs quickly \\
Sitting: & On dining-room chair, with arms folded, slowly stand and sit \\
Standing: & On tiptoe, with support, slowly bend knees to sit on heels and stand up
\end{tabular}

programme of home exercises and encouraged to do each one 10 times, at least once a day, and to take a daily walk. The importance of the daily exercise programme and the antismoking policy were emphasised. During this visit patients were assessed for the total number of step-ups on and off a bench $30 \mathrm{~cm}$ high before the onset of claudication pain, and their claudication walking distance was measured in number of lengths of the gymnasium.

For the next three weeks patients attended on one afternoon each week for exercises designed to improve the function of the legs. These included step-ups, straight-leg raising, sitting and standing, knee-bending exercises, and pulling the heels along the floor while sitting on a mat. The home exercise programme was also practised. At the end of each session, after adequate rest periods, their claudication distance was measured in number of lengths of the gymnasium. All patients were re-evaluated by the physiotherapist at six weeks and at six months.

\section{Results}

Clinical assessment, pulse volume recordings, and Doppler pressure measurements were used to categorise patients into three groups: those with iliac artery occlusion alone (three patients), those with iliac stenosis and superficial femoral artery occlusion (nine) and those with superficial femoral artery occlusion and tibial vessel disease (eight). Superficial femoral artery occlusion alone did not cause claudication at 250 yards $(230 \mathrm{~m})$. One patient with a typical history of claudication showed no evidence of peripheral vascular disease on laboratory testing and was therefore excluded. Mean resting ankle pressure in the remaining 20 patients was reduced to $84 \pm \mathrm{SE} 6 \mathrm{~mm} \mathrm{Hg}$ and the ischaemic response after treadmill exercise was a fall in mean ankle pressure to $50 \pm 8 \mathrm{~mm} \mathrm{Hg}(\mathrm{p}<0.005)$. The mean amplitude of the resting ankle pulse volume recording was $11 \pm 2 \mathrm{~mm}$, which also fell in response to exercise to $5 \pm 2 \mathrm{~mm}$ $(\mathrm{p}<0.001)$.

Patients who adhered rigidly to the daily exercise programme showed the greatest improvement. Eighteen patients performed $75 \%$ more step-ups $(42 \pm 6$ to $64 \pm 7 ; \mathrm{p}=0.01)$ and walked $80 \%$ further $(329 \pm 33$ yards to $588 \pm 51$ yards $(299 \cdot 4 \pm 30 \mathrm{~m}$ to $535 \cdot 1 \pm$ $46.4 \mathrm{~m}) ; \mathrm{p}<0.001)$ in the gymnasium. Other benefits included increased wellbeing in 19 patients whether their walking distance had improved or not.

A slight improvement in treadmill walking distance, exercise time on a bicycle ergometer, resting and post-exercise ankle systolic pressures, and pulse volume amplitudes at the end of the study were not significant. No patient suffered any ill effect from the exercise sessions, and in particular there was no provocation of angina pectoris or myocardial infarction.

Two patients whose claudication worsened during the study were admitted to hospital for an arteriogram. The response to the advice to stop smoking was variable; six smokers managed to stop completely and five cut down to under 10 cigarettes a day. Six could not or would not cut down, and three had stopped before the study. Unfortunately, those who cut down or stopped smoking were not rewarded with better results than those who did not.

\section{Discussion}

Our results confirm that a substantial improvement in walking distance and step-ups may be achieved in most patients with claudication who undergo exercise training. The increased tolerance to exercise on a bicycle ergometer and by treadmill testing was less striking than in the studies by Larssen and Lassen ${ }^{3}$ and Ekroth et al, ${ }^{5}$ in which treadmill walking time more than doubled after exercise training. The reasons for this difference are not clear but may be related to treadmill speed and gradient. The lack of improvement in pulse volume and ankle pressure confirms the findings of Dahllöf et $a l^{4}$ and Jonason et al. ${ }^{6}$ Several authors have failed to show a significant increase in calf blood flow after exercise training by either using xenon-133 clearance cr $^{3}$ or testing with venous-occlusion straingauge plethysmography. ${ }^{5}$ Improvement in walking distance cannot therefore be ascribed to increased blood flow from the development of collaterals, as some have suggested. ${ }^{2}$ Other proposed mechanisms include redistribution of muscle blood flow within the leg, increased metabolic activity in exercisetrained skeletal muscle, ${ }^{8}$ improved walking efficiency, and increased pain tolerance, but there is little evidence to support any of these explanations.

A diet and exercise regimen was recently shown to improve mental acuity and to have beneficial effects on psychological factors and personality in elderly people with cardiovascular disease. ${ }^{9}$ Our patients felt physically and mentally much better as their exercise ability improved. They also remarked on the benefits of meeting other people with a similar mild disease in contrast with those met in the vascular clinic waiting area, who occasionally included amputees. The class developed a group identity, and each member was encouraged by the group's success. Many patients - aware and afraid of claudication-had curtailed any exercise so that they stopped walking before pain developed. Under supervision and encouraged by others in the group, however, they would continue for longer after the onset of pain.

We believe that similar training at home would have been less effective than the exercise class. As others have found, the improvement in symptoms was unrelated to the sites of arterial lesions and occurred with both aortoiliac and femoropopliteal occlusive disease. The rate of surgical intervention $(10 \%)$ was similar to that in other studies. ${ }^{10}$ The improvement in walking distance occurred without the use of vasodilators, though most patients had already taken these drugs with varying effect. Although this study was confined to patients with intermittent claudication, Foley ${ }^{1}$ and Jonason et $a l^{6}$ showed that patients with ischaemic rest pain or even trophic changes could benefit from exercise training. Less improvement would be likely in elderly patients or those with combined limb ischaemia and cardiorespiratory disease. Patients with neurogenic claudication would probably not benefit at all, which emphasises the importance of confirming the haemodynamic effects of 
limb ischaemia in a vascular laboratory if the clinical diagnosis of claudication is in doubt.

\section{References}

1 Foley WT. Treatment of gangrene of the feet and legs by walking. Circulation 1957;15:689-700.

${ }^{2}$ Skinner JS, Strandness DE. Exercise and intermittent claudication. II. Effect of physical training. Circulation $1967 ; 36: 23-9$.

${ }^{3}$ Larssen OA, Lassen NA. The effect of daily muscle exercise in patients with intermittent claudication. Lancet 1966;ii:1093-6.

${ }^{4}$ Dahllöf AG, Holm J, Schersten T, Sivertssen R. Peripheral arterial insufficiency; effect of physical training on walking tolerance calf blood flow and blood flow resistance. Scand F Rehabil Med 1976;8:19-26.
5 Ekroth R, Dahllöf A, Gundevall B, Holm J. Physical training of patients with intermittent claudication: indications, methods and results. Surgery $1978 ; 84: 640-3$.

${ }^{6}$ Jonason T, Jonzon B, Rinqvist I, Oman-Rydberg A. Effect of physical training on different categories of patients with intermittent claudication Acta Med Scand 1979;206:253-8.

${ }^{7}$ Leading article. Intermittent claudication. Br Med $\mathcal{F} 1976$;i :1165-6.

${ }^{8}$ Gollnick PD, Armstrong RB, Saubert CW, et al. Enzyme activity and fiber composition in skeletal muscle of untrained and trained men. F Appl Physiol 1972;33:312-9.

- Merzbacher CF. A diet and exercise regimen: its effect upon mental activity and personality; a pilot study. Percept Mot Skills 1979;48 367-71.

${ }^{10}$ McAllister FF. The fate of patients with intermittent claudication managed non-operatively. Am $\mathcal{F}$ Surg 1976;132:593-5.

(Accepted 21 March 1980)

\section{SHORT REPORTS}

\section{Primary hyperparathyroidism presenting with visual failure and palatal swelling}

We report the case of a patient with primary hyperparathyroidism in which the presenting symptoms included unilateral visual failure. This recovered completely after removal of a parathyroid adenoma.

\section{Case report}

A 47-year-old housewife presented with a midline palatal swelling for 10 weeks. She also complained that vision in her right eye had been diminishing over four weeks. She had had sciatica two years previously and still had diffuse back pain. She was edentulous, wearing full upper and lower dentures. There was a smooth, fairly soft swelling $3 \mathrm{~cm} \times 1.5 \mathrm{~cm}$ in the midline at the posterior aspect of the hard palate, displacing the upper denture, and two small fusiform swellings on the lateral aspects of the maxillary alveolus in the incisor regions. Slight localised bossing of the left frontal bone was apparent. Visual acuity in the right eye was very poor and deteriorated to perception of light over 10 days. Corneal calcification was noted bilaterally at the limbal equator. The retinal arteries in the right eye appeared slightly attenuated and the pupil was sluggish, but there was no lens opacity, myopia, proptosis, impairment of ocular movement, or papilloedema and no ocular lesion sufficient to account for the loss of vision. Visual acuity in the left eye was normal. $X$-ray examination showed ill-defined radiolucent areas in the maxillary alveolus coinciding with the fusiform swellings. The right optic foramen appeared on tomograms as an ill-defined region of radiolucency with no clear margin. The left optic foramen appeared normal. The phalanges showed subperiosteal erosions. There were cystic changes in the pelvic girdle, ribs, and frontal bone.

Serum concentrations measured were as follows: calcium $3.85 \mathrm{mmol} / 1$ $(15.4 \mathrm{mg} / 100 \mathrm{ml}$ ) (normal $2 \cdot 1-2.6 \mathrm{mmol} / \mathrm{l}(8 \cdot 4-10.4 \mathrm{mg} / 100 \mathrm{ml}))$; phosphate $0.72 \mathrm{mmol} / \mathrm{l}(2.3 \mathrm{mg} / 100 \mathrm{ml})$ (normal $0.8-1.4 \mathrm{mmol} / \mathrm{l}(2.5-4.5 \mathrm{mg} / 100 \mathrm{ml})$ ); albumin $45 \mathrm{~g} / 1$ (normal 34-50 g/1); alkaline phosphatase $303 \mathrm{IU} / 1$ (normal 20-90 IU/1); parathyroid hormone $6.65 \mu \mathrm{g} / 1$ (normal $<1.0 \mu \mathrm{g} / \mathrm{l}$ ) by radioimmunoassay using a human parathyroid hormone standard; creatinine $91 \mu \mathrm{mol} / 1(1.03 \mathrm{mg} / 100 \mathrm{ml}$ ) (normal $50-120 \mu \mathrm{mol} / 1(0.56-1.35 \mathrm{mg} / 100 \mathrm{ml})$ ). An excision biopsy specimen of the palatal swelling showed a vascular, fleshy tumour completely eroding the bone of the hard palate, macroscopically typical of a giant-cell lesion. Histologically it was a giant-cell lesion containing a large amount of osteoid, some showing early ossification.

A large single tumour of the left inferior parathyroid gland weighing six grams was removed. Histologically it was typical of a parathyroid chief-cell adenoma. Postoperatively all the biochemical abnormalities resolved. She was given $0.5-2 \mu \mathrm{g}$ 1-alphahydroxycholecalciferol daily for 12 weeks, by when the alkaline phosphatase concentration had returned to normal. Radiological healing of the skeletal lesions was subsequently confirmed. In particular, the right optic foramen became sharply defined, normal in size, and with a slightly sclerotic border. Vision returned in the right eye within two weeks of the parathyroidectomy. Acuity was $6 / 9$ after six weeks and 6/5 after five months.

\section{Comment}

This patient had skeletal changes affecting many bones because of primary hyperparathyroidism. The palatal giant-cell tumour was typical of lesions described in this condition and well known to affect the jaw bones. ${ }^{1}$ Corneal calcification is associated with hypercalcaemia ${ }^{2}$ and papilloedema has been reported, ${ }^{3}$ but visual failure due to hyperparathyroidism has not been recorded. It may have resulted from distortion of the neurovascular bundle in the optic canal by another giant-cell tumour, and this hypothesis is supported by the return of vision and restoration of the optic foramen (radiologically) that followed removal of the parathyroid adenoma.

We thank Drs A R Manners, E Dillon, and A K Lamballe for radiologica advice, Drs $\mathrm{R}$ Lawler and $\mathrm{H}$ E Simpson for histological reports, and the Supraregional Assay Service (Middlesex Hospital Laboratory, London) for measurements of parathyroid hormone.

${ }^{1}$ Black BK, Ackerman LV. Tumours of the parathyroid. Cancer 1950; $3: 415-44$.

2 Cogan DG, Albright F, Bartter FC. Hypercalcemia and band keratopathy. Arch Ophthalmol 1948;40:624-38.

${ }^{3}$ Murphy KJ. Papilloedema due to hyperparathyroidism. $\mathrm{Br} \mathcal{F}$ Ophthalmol $1974 ; 58: 694-7$.

(Accepted 4 March 1980)

North Tees General Hospital, Stockton on Tees, Cleveland TS19 8PE D CARR, MB, MRCP, consultant physician

B J P HALL-PARKER, LMSSA, DO, consultant ophthalmologist B SUMMERSGILL, BCHD, FDSRCS, consultant oral surgeon R W THOMSON, FRCS, consultant surgeon

\section{Chronic thrombocytopenic purpura associated with toxoplasmosis}

Many aetiological factors play a part in the pathogenesis of idiopathic thrombocytopenic purpura. Among these are viral infections, ${ }^{1}$ drugs, and other autoimmune diseases. ${ }^{2}$ Many cases are truly idiopathic. We report the case of a child with chronic thrombocytopenic purpura associated with toxoplasmosis. The parasite Toxoplasma gondii has not been reported as a possible cause of thrombocytopenic purpura.

\section{Case report}

A 2-year-old girl presented with purpura. One month earlier she had had a fever, but the cause was not known. Physical examination showed purpura, enlarged lymph nodes, and mild hepatosplenomegaly. The platelet count was $10-20 \times 10^{9} / 1 \quad\left(10000-20000 / \mathrm{mm}^{3}\right)$. The result of bone marrow examination was unhelpful. After a short course of steroid treatment the purpura and thrombocytopenia disappeared. A Sabin-Feldman dye test, performed because of an enlarged spleen and liver and lymphadenopathy, was positive at a titre of $1 / 4096$. Three months later the titre was $1 / 1024$, and one year later $1 / 256$. 